\title{
Mujeres y estructuras patriarcales: el papel de los movimientos feministas
}

\section{Aldana Florencia Romano' Universidad Nacional de San Luis}

\section{Aporte de Estudiante}

Resumen: El siguiente ensayo realiza un análisis del patriarcado como hecho social vigente en palabras de Emile Durkheim (1895 2001), al mismo tiempo, evidencia cómo ha ido delimitado a lo largo de la historia la posición subjetiva de mujeres y varones de acuerdo a su género. Para ello, se acude a los conceptos planteados por Durkheim y por Simone de Beauvoir (1949 2016) sobre la sociedad en la que habitamos. El texto pretende dejar en claro que el patriarcado como hecho social no es eventual, sino que se crea a partir de creencias y modelos que se instauran en la sociedad, estableciendo pautas de conducta, normas e incluso sanciones que pueden producir la marginación de quienes no las acatan. A su vez, se evidencia cómo desde los movimientos de protesta, encabezados por el feminismo, se busca romper progresivamente con ese modelo patriarcal, principalmente buscando reivindicar el papel de la mujer desde una mirada de igualdad entre ambos sexos-géneros. Estos movimientos demandan un cambio de paradigma, que provoque un quiebre en la forma de pensar, actuar y sentir que tienen los sujetos socializados en las estructuras patriarcales, basándose en la liberación de la mujer y del varón, eliminando jerarquías y desigualdades entre ambos géneros.

\section{Introducción}

Desde que hombres y mujeres habitan la tierra, la sociedad ha sido caracterizada por ser afín a la estructura dominante del patriarcado. Se establecieron formas, modos de pensar, actuar y sentir que giraban en torno a la idea del hombre como un ser superior a la mujer; un pensamiento que se encuentra vigente incluso en pleno siglo XXI.

Como expresa Simone de Beauvoir en su célebre obra El Segundo Sexo (1949 2016), "A un hombre no se le ocurriría la idea de escribir un libro sobre la singular situación que ocupan los varones en la Humanidad. Si quiero definirme, estoy obligada antes de nada a declarar: <<Soy una mujer >>... Un hombre no comienza jamás por presentarse como individuo de un determinado sexo: que él sea hombre es algo que se da por supuesto" (p.10), es decir que la idea de cómo está posicionado el hombre en esta sociedad no se discute y jamás se ha debatido, ya que se ha institucionalizado el patriarcado y con ello estructuras

\footnotetext{
${ }^{1}$ Estudiante de la Maestría Sociedad e Instituciones de la Universidad Nacional de San Luis. Abogada. Becaria en el proyecto de investigación Juventudes Contemporáneas (U.N.S.L.). Correo electrónico: romanoaldana@gmail.com
} 
desiguales, que cuestionan constantemente el papel de la mujer, concibiéndola en un segundo plano, en una posición de disparidad respecto del varón que va más allá de lo biológico.

Por ello, en este texto se realiza un breve análisis de la realidad coyuntural en la cual se posicionan las mujeres en la sociedad actual, y el rol importante que juegan aquellos movimientos de protesta encabezadas por los feminismos, que reclaman por un posicionamiento de igual a igual entre mujeres y varones en pleno siglo XXI.

\section{El Patriarcado}

Antes de comenzar a analizar esta forma de organización que es propia de nuestra sociedad, debemos detenernos en definir qué consideramos por sociedad. Para Emile Durkheim, en su obra Las reglas del método sociológico (1895 2001), la sociedad es concebida como una totalidad sui generis - sin género- que se compone por un conjunto de normas que se les imponen a los sujetos; normas que no son necesariamente escritas y que otorgan un sentido a un orden social. Es así que "la sociedad siempre ha sido masculina; el poder político siempre ha estado en manos de los hombres" (Beauvoir, d, S. 2016, p.31), ergo, las funciones públicas desde tiempos primitivos -de hecho previos a la colonización²siempre han sido ejercidas por el varón, incluidas las relaciones de reciprocidad; se trata de igual a igual a la idea del individuo varón con otro individuo varón. Este tipo de pensamiento, no es sólo exterior al individuo que conforma esta sociedad, sino que están dotados de un poder imperativo y coercitivo en virtud del cual se le imponen a él, quiera o no (Durkheim, 1895 2001). Por ende, podemos concebir al patriarcado como un hecho social propiamente dicho. Ahora bien, ¿Qué entendemos por hecho social? Durkheim (1895 2001) lo define como modos de actuar, pensar, sentir, exteriores al individuo, y que están dotados de un poder de coacción en virtud del cual se imponen sobre él (p.41). Son maneras de vivir socialmente, son las unidades de análisis que nos coaccionan a actuar de determinada manera, que llegan a institucionalizarse.

Se pueden formular las siguientes preguntas, ¿Por qué no se ha cuestionado la posición predominante del hombre en la posibilidad de obtener mayor autonomía económica y a partir de ello ser los principales contribuyentes en la economía de los hogares? O bien, ¿Por qué se ha naturalizado que el varón no puede mostrar sus emociones en público? Porque como expone la autora del Segundo Sexo (1949 2016), "Desde el origen de la Humanidad, su privilegio biológico ha permitido a los varones afirmarse exclusivamente como sujetos soberanos; jamás han abdicado de ese privilegio; en parte han alienado su existencia

\footnotetext{
2 Se puede consultar el texto de Rita Segato (2011).
} 
en la Naturaleza y en la mujer; pero enseguida la han reconquistado; condenada a representar el papel del Otro" (p. 35). Se ha representado históricamente al varón como perteneciente al sexo-género fuerte, cuya fortaleza lo posiciona como el más idóneo -por supuestos atributos biológicos- para obtener determinados empleos, limitando sus posibilidades de expresar comportamientos que denotarían debilidad -que son atribuidos a las mujeres- y que implican demostrar sentimientos y emociones ${ }^{3}$.

Cuando estos hechos sociales, que no son eventuales, crean creencias y modelos, se instituyen en la sociedad estableciendo pautas, normas de conducta e incluso sanciones hacia los sujetos que no se adecuan a ellos. Por ejemplo, la mujer en las culturas romanas, "estaba excluida de los asuntos públicos, todo "oficio viril" le está rigurosamente prohibido; y en su vida civil es una eterna menor. No se le niega directamente su parte en la herencia paterna, pero le impiden disponer de ella por un medio indirecto: se la somete a la autoridad de un tutor..." (Beauvoir, d, S. 2016, p. 37).

Estas prácticas y creencias patriarcales nos son trasmitidas por generaciones anteriores, que las recibimos y las adoptamos porque están investidas de una autoridad particular que la educación nos ha enseñado a reconocer y respetar (Durkheim, 1895 2001).

\section{Un cambio de paradigma: la lucha de los movimientos feministas}

A pesar de estar instituidas estas creencias y prácticas, no puede concebirse al patriarcado como el único hecho social donde existe una organización definida, sino que, a pesar de mantener su vigencia en la actualidad, a partir del siglo XX comenzó a perfilarse otro hecho social, encabezado desde el feminismo. Estas corrientes sociales, definidas así por Durkheim (1895 2001), son grandes movimientos de entusiasmo, de indignación, que no tienen lugar de origen en una conciencia particular, sino que llegan nuevamente desde afuera y buscan cambiar el paradigma.

Los movimientos de protesta que provienen del feminismo buscan un cambio en la forma de pensar, actuar y sentir de los sujetos, basados en la liberación de la mujer -y del varón también- eliminando las prácticas que provienen del patriarcado, donde se establecen jerarquías y desigualdades entre los sexos-géneros (Gamba, 2008). El pensamiento feminista propugna un sistema de ideas, basado en el estudio y análisis de la posición que tuvo la mujer a lo largo de la historia en los distintos ámbitos de la sociedad, que pretende transformar las

\footnotetext{
${ }^{3}$ Es posible reflejar lo arraigado de estas representaciones incluso con una referencia de Augusto Comte, en su Lección 50 del Curso de filosofía positiva, publicado en 1839, quien afirma que la mujer carece de capacidad para cumplir con la continuidad e intensidad necesarias que requiere una labor mental, ya sea por la debilidad intrínseca de su facultad racional o por su mayor sensibilidad física y moral, que es hostil a la concentración y a la abstracción científica (Guerra Cunningham, 2010).
} 
relaciones establecidas que se basan en una asimetría notoria y opresión del género femenino por considerarlo débil e incapaz. A su vez, tal como describe Gamba (2008):

El Feminismo consiguió colocar la cuestión de la emancipación de las mujeres en la agenda pública desde mediados de los setenta... Se produce una importante institucionalización del movimiento con la proliferación de ONG, la participación de feministas en los gobiernos y organismos internacionales, y la creación de ámbitos específicos en el Estado. Desde su espacio en las universidades el feminismo aumentó la investigación y la construcción de tesis, profundizando y complejizando sus reflexiones con mayor rigor académico (p.5).

Ante las duras críticas sobre las estructuras patriarcales que se realizaron desde los movimientos feministas, las instituciones que no acuerdan con sus reclamos, en donde predomina el "viejo" paradigma, intentaron demostrar la inferioridad de la mujer con respecto al varón, no solo desde la religión, la filosofía y la teología, como antes, sino también desde la ciencia en biología, psicología experimental, etc.

\section{Palabras finales}

El patriarcado es un hecho social vigente desde tiempos primitivos, que ha imperado en la sociedad, estableciendo la forma de pensar, actuar y de sentir de los sujetos de modo coactivo, y esta coacción no ha sido cuestionada hasta comienzos del siglo XX por ningún sector social.

Si bien las ideas feministas se fueron cultivando desde el siglo XIII con Guillermine de Bohemia, que promulgaba la idea de crear una iglesia de mujeres (Gamba, 2008), encontramos recién el auge de las teorías feministas en los siglos XIX y XX. Estas proponen un cambio de paradigma con respecto al papel de la mujer en la sociedad; se busca una nueva identidad para el sujeto femenino, que lo redefina en lo personal y en lo social. Se requiere de una transformación en las estructuras económicas, en las relaciones entre los sexos-géneros, una igualdad jurídica y política.

Estas nuevas creencias e ideales, que comienzan a proliferar cada vez más en la sociedad, van instituyendo nuevas minorías, creando normas de conductas novedosas, e incluso sanciones a lo que antes estaba concebido como apropiado. No obstante, el desafío del feminismo, aún está vigente. El hecho social del patriarcado se encuentra arraigado en la 
sociedad en la cual habitamos y se transmite intergeneracionalmente, en consecuencia, estos movimientos deberán encontrar las estrategias necesarias para articular sus luchas e impulsar las transformaciones que demande la sociedad actual, con el fin de transformar el concepto que se tiene sobre la posición de la mujer en la sociedad desde una mirada de igualdad entre los sexos-géneros.

\section{Referencias bibliográficas}

Beauvoir, de, S. (1949 2016). El Segundo Sexo. París: Editorial Debolsillo.

Cunningham Guerra, L. (2010). Feminismo o ideología liberal en el pensamiento de Eugenio María de Hostos. Alicante: Biblioteca Virtual Miguel de Cervantes.

Durkheim, E. (1895 2001). Las reglas del método sociológico. D. F. México: Editorial Fondo de Cultura Económica

Gamba, S. (2008). Diccionario de estudios de género y feminismos. Buenos Aires: Editorial Biblos.

Segato, R. L. (2011). Género y colonialidad: en busca de las claves de lectura y de un vocabulario estratégico descolonial. En K. Bidaseca y V. Vazquez Laba (Comps.). Feminismo y poscolonialidad. Descolonizando el feminismo desde y en América Latina, (pp. 17-48). Buenos Aires: Ediciones Godot. 